D.O.I: $10.3895 / \mathrm{S} 1808-04482012000200004$

\title{
CONTROLE DE ESTOQUE: A CONTRIBUIÇÃO DA CONTAGEM CÍCLICA DE MATERIAIS EM UM INSTITUTO DE ODONTOLOGIA
}

\section{INVENTORY CONTROL: THE CONTRIBUTION OF THE CYCLE COUNTING OF MATERIALS IN AN INSTITUTE OF DENTISTRY}

\author{
Everton Drohomeretski ${ }^{1}$; Juliano Anderson de Souza ${ }^{2}$ \\ ${ }^{1}$ FAE Centro Universitário - FAE - Curitiba - Brasil \\ profeverton.d@hotmail.com \\ ${ }^{2}$ PUC-PR - Curitiba - Brasil \\ jas_juliano@yahoo.com.br
}

\begin{abstract}
Resumo
A busca por métodos efetivos de controle de estoque que reflitm dados confiáveis para o planejamento e execução das operações passa a ser um requisito para que as organizações sobrevivam no mercado. Assim a qualidade das informações dos saldos de estoque faz com a eficiência dos processos aumente. Para isso, é necessário utilizar métodos que auxiliem no controle do estoque, aumentando o percentual de acuracidade de estoque. Nesta linha, o presente trabalho tem por objetivo analisar a contribuição da contagem cíclica no controle de estoque em um instituto de odontologia. Para alcançar o objetivo proposto foi utilizado o estudo de caso como abordagem metodológica. Com a implantação da contagem cíclica de materiais conseguiu-se identificar quais fatores estavam impactando nas informações dos saldos de estoque, com isso o instituto implantou ações para eliminar as principais causas das divergências. Os resultados da implantação foram significativos, pois o aumento foi de 14,77\% na acuracidade de estoque.
\end{abstract}

Palavras-chave: Controle de estoque; acuracidade; contagem cíclica; instituto odontologia.

\section{Introdução}

O elevado mix de produtos faz com que os estoques dentro das organizações cresçam. Dessa forma torna-se necessário não somente um sistema computacional adequado, mas também ferramentas gerenciais que serviram de suporte para as tomadas de decisão. Ou seja, mecanismos que permitiram um diagnóstico claro e abrangente da situação real da atual gestão, onde as decisões deverão ser alinhadas às estratégias da empresa, assim buscam-se a maximização dos resultados.

Existem vários métodos que objetivam auxiliar as empresas na busca por resultados cada vez mais significativos. Entre elas os métodos que acompanham o fluxo de materiais, garantindo uma alta no percentual de acuracidade dos estoques. Nesta linha, foi desenvolvido o presente trabalho, tendo como base analisar a contribuição da contagem cíclica para melhorar a falta de 
qualidade nas informações, relativas aos saldos de estoque de um instituto de odontologia, voltado à formação de profissionais neste segmento.

Com isso, o presente artigo objetiva analisar a contribuição da contagem cíclica para o controle de estoque de um instituto de odontologia.

É crescente o número de estudos voltados à identificação de métodos para melhorar a acuracidade de estoque. No entanto, boa parte das pesquisas atuais visa identificar como a tecnologia impacta na acuracidade de estoque. Além disso, quando é utilizado o estudo de caso como estratégia de pesquisa, os estudos são realizados em empresas na área de varejo e alguns estudos na área industrial. Já na área de serviços, mais especificamente na área da saúde, verificase uma carência de estudos. Tendo em vista as particularidades no sistema de controle de estoque, tipo de produto, entre outros. Assim faz-se necessário o investimento em investigações neste segmento de mercado.

O artigo está estruturado em 6 seções, incluindo esta introdução. Na segunda seção, apresentam-se o método de pesquisa. Na terceira seção apresentam-se o referencial teórico. $\mathrm{Na}$ quarta seção, é apresentada a descrição dos casos. Já na quinta seção, é realizada a análise dos casos. Por fim, na sexta seção são relatadas as considerações finais da pesquisa.

\section{Método de Pesquisa}

Esta seção tem o objetivo de demonstrar o método de pesquisa aplicado para o desenvolvimento do presente estudo, bem como os meios para a coleta e análise dos dados pertencentes à pesquisa.

Como abordagem metodológica, utilizou-se o estudo de caso. Por meio de visitas realizadas no instituto no período de março de 2009 a julho de 2009, observou-se deficiência na gestão de estoque no que se diz respeito à acuracidade. Tendo como parâmetro para avaliação o referencial de Corrêa et al (2001), que aponta como índice aceitável 95\% de acertos entre os dados apresentados pelo sistema e o saldo físico dos produtos, onde tal percentual deve ser mantido para um adequado atendimento às suas demandas.

Para coleta de dados foram utilizados os seguintes critérios:

a) Entrevista semi-estruturada com o responsável pelo setor de controle de estoque;

b) Visitas in loco mensais;

c) Avaliação dos relatórios de inventário;

d) Observações evidenciadas nos processos. 
Já a análise dos dados será realizada por meio da comparação entre os índices de acuracidade de estoque, desde o período que antecede a implantação da contagem cíclica, até o índice resultante das contagens pós a implantação da contagem cíclica. A Figura 1 sintetiza o método de pesquisa adotado.

Figura 1 - Estrutura da pesquisa

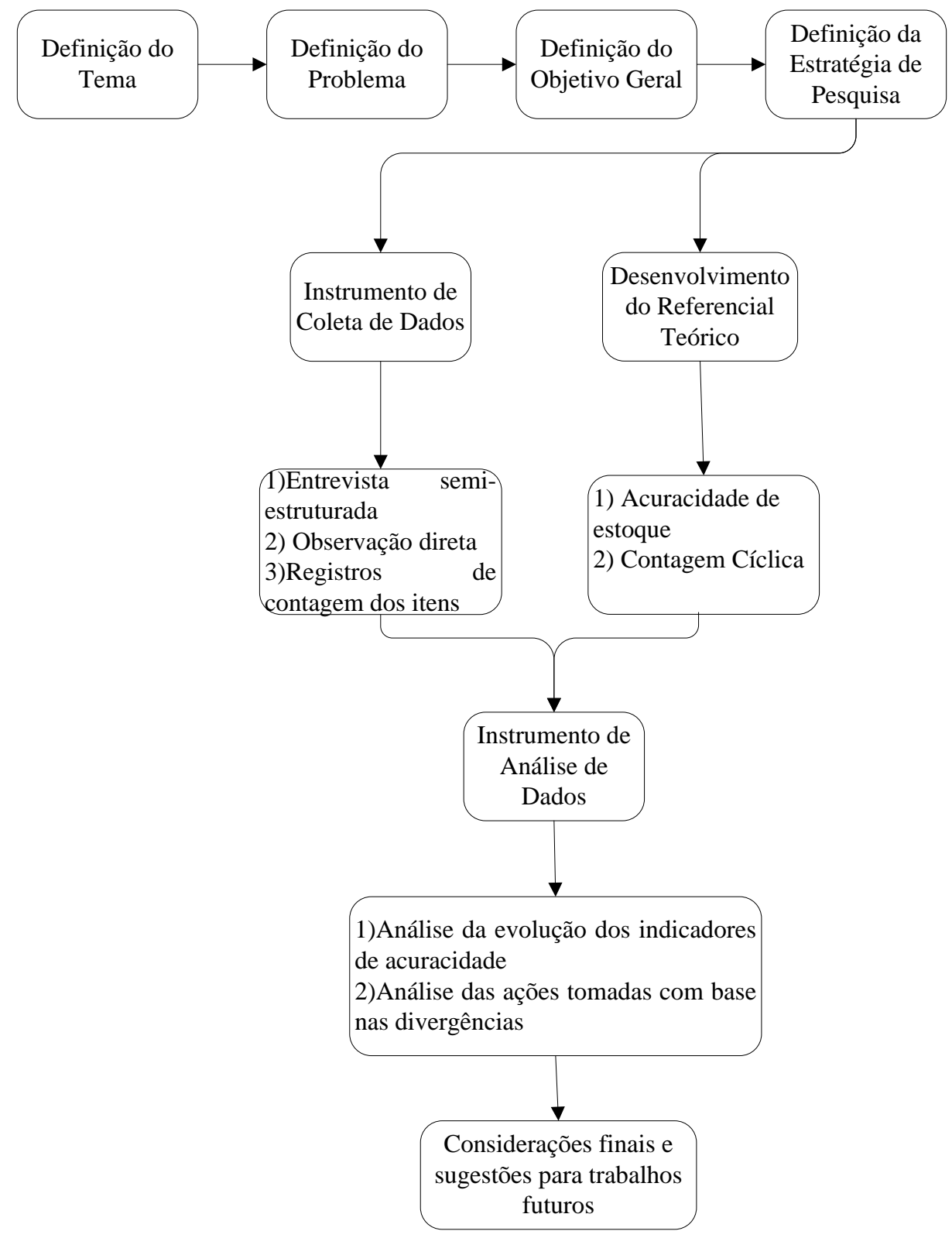

Fonte: Os autores

\section{Referencial Teórico}

Nesta seção será apresentado o referencial teórico que tem por objetivo fornecer embasamento para o presente estudo, dessa forma será dividido nos seguintes pontos: acuracidade de estoque, tipos de inventários e contagem cíclica. 


\subsection{Acuracidade de Estoque}

De acordo com Sheldon (2004) a acuracidade de estoque pode ser definida como a relação entre o saldo identificado fisicamente no estoque com o saldo registrado no sistema de controle de estoque. A equação para verificação e mensuração dos dados de acurácia é definida da seguinte forma:

$\mathrm{IAE}=\frac{\mathrm{Sf}}{\mathrm{Ss}} \mathrm{x} 100$

Onde:

IAE: Índice de Acuracidade de Estoque

Sf: Saldos verificados através das contagens dos produtos;

Ss: Saldos apontados pelo sistema de gestão utilizado, controle de entradas e saídas.

O controle físico dos materiais armazenados é fundamental para o sucesso dos processos posteriores à armazenagem, pois qualquer avaria pode comprometer o atendimento a demandas. Para Arnold (1999) como os estoques são formados por produtos tangíveis, estes podem ser perdidos ou roubados, assim torna-se necessário um sistema que auxilie de forma eficaz no controle do stock keeping unit (SKU's). Para um bom controle dos saldos físicos, o sistema de numeração de peças e um sistema transação simples e bem-documentado são extremamente importantes, onde essas transações podem ser divididas em quatro passos, sendo eles:

a) Identificação do item;

b) Conferência da quantidade;

c) Registro da transação;

d) Realização da transação fisicamente.

Esses quatro passos se bem direcionados resultaram em menores erros nos registros de estoque, pois as informações de saldos podem comprometer diretamente os processos das organizações refletindo no cliente final. Ou seja, se os registros de quantidades não forem precisos, ocasionaram faltas de produtos, entregas atrasadas, vendas perdidas, baixa produtividade e excesso de estoque.

O controle das informações dentro dos processos deve ser padronizado, onde toda circulação ou movimentação de material deve ser identificada e acompanhada por documentos que facilitem a compreensão do porque aquela movimentação é necessária e ainda qual é o destino das peças, assim o percentual de erro tende a ser reduzido, pois os processos de movimentação estão documentados. 
O Quadro 1 identifica quais documentos devem ser utilizados para os processos de controle de estoque.

Quadro 1- Processos e documentos de estoque

\begin{tabular}{|l|l|}
\hline \multicolumn{1}{|c|}{ Movimentação } & \multicolumn{1}{c|}{ Documento } \\
\hline Recebimento de compras & Pedido de compras \\
\hline Recebimento de produção & Ordem de fabricação \\
\hline Recebimento de devolução & Nota fiscal ou romaneio \\
\hline Saída de vendas & Pedido de venda/nota fiscal \\
\hline Saída de reposição & Nota fiscal de devolução \\
\hline Saída de requisição & Requisição de material \\
\hline Saída para produção & Requisição de peça da ordem de \\
\hline Saída para inspeção de qualidade & Requisição de material \\
\hline
\end{tabular}

Fonte: Adaptado de Accioly et al (2008)

Para Fernandes e Pires (2005) essa preocupação com o problema de diferenças de saldos de estoque tende a diminuir para muitas empresas, já que muitas utilizam tecnologias de ponta na gestão de estoques e grandes armazéns. Mas infelizmente essa não é a realidade de muitas organizações, pois nem todas possuem capital suficiente para investimentos em grandes tecnologias, assim a rotina nos processos é cercada de problemas que afetam a acurácia e tornam as informações ineficientes, refletindo diretamente no planejamento de materiais.

Pode-se notar que a confiabilidade nas informações de estoque é essencial para o direcionamento correto das atividades e de todo o planejamento de estoque. Assim organizações investem cada vez mais para que os erros de informações sejam reduzidos, não só em equipamentos e tecnologias, mas em pessoas. Para a verificação das informações, empresas utilizam métodos de inventários físicos, a prática a ser utilizada dependerá dos processos e particularidades de cada organização, onde devem ser identificados dois pontos importantes, sendo: o tipo de material estocado e a sua importância.

\subsection{Tipos de Inventário Físico}

A contagem dos itens em estoque pode ser chamada de inventários físicos. Um procedimento que visa apurar qual é o percentual de erros existentes entre o saldo físico real do produto e aquele apresentado pelo sistema computadorizado. Ou seja, qual é acurácia das informações de saldos. Tais erros podem comprometer o nível de serviço e assim causar prejuízos as organizações. Neste sentido Viana (2000) define os inventários físicos como métodos de auditorias permanentes de estoques, que tem por objetivo garantir a confiabilidade das informações, ponto necessário para que os processos funcionem com o grau de eficiência desejado. 
Os métodos de inventários de estoque comparam as quantidades dos itens, não se preocupando diretamente com o valor dessas peças, pois para o operacional o que importa é se os itens estão em estoque ou não. Na visão de Sucupira e Pedreira (2009) as empresas que se preocupam somente com inventários gerais, aqueles de final de ano e visam somente os custos dos produtos, possuem uma visão patrimonialista e não de perfeição nas atividades, esse tipo de levantamento acaba mascarando os erros de sobras e faltas, pois essas quantidades acabam sumindo quando contabilizadas, ou seja, a falta de uma peça é coberta pela sobra de outra, e assim os erros de saldos não são identificados.

Para Gasnier (2002) existem diferentes métodos de elaboração de inventários, cada qual adequado a diferentes necessidades, assim o primeiro passo é conhecer e definir qual é o melhor método a ser utilizado. Como já detalhado o inventários físicos é o processo de contagem dos itens de estoque, essas contagens podem ocorrer uma única vez no ano, ou várias vezes, onde o procedimento adotado dependerá da política gerencial de cada empresa. Para Sucupira e Pedreira (2009) existem quatro diferentes métodos de inventários, esses são demonstrados no Quadro 2.

Quadro 2 - Métodos de inventários físicos

\begin{tabular}{|c|c|}
\hline Tipo de inventário & Visão do método \\
\hline Inventário geral & Contábil, preocupação com o valor dos ativos. \\
\hline Inventário dinâmico & Economizar recursos operacionais do \\
& almoxarifado. \\
\hline Inventário cíclico/Contagem & Prevenção de erros, manter as informações \\
Cíclica & corretas. \\
\hline Inventário por amostragem & Identificar se os métodos de controle são \\
& eficientes. \\
\hline
\end{tabular}

Fonte: Adaptado de Sucupira e Pedreira (2009)

A contagem cíclica, foco deste estudo, é realizada de maneira continua, normalmente com datas pré-definidas, utiliza-se normalmente como padrão para a seleção dos itens a sua popularidade.

\subsection{Contagem Cíclica de Materiais}

A atividade de contagem cíclica dos materiais é um procedimento que visa contar todos os itens do estoque em datas pré-definidas e com os itens já definidos, utiliza, por exemplo, a classificação ABC como parâmetro para sua realização. Na visão de Accioly et al (2008) a contagem cíclica é considerada uma contagem continua dos itens, onde são definidas previamente as datas para estas, podendo ser mensal, semanal ou diária. 
De acordo com Wilson (1995) a contagem cíclica apresenta dois objetivos principais:

1. Motivar os funcionários para diminuir os erros nos registros de estoque;

2. Identificar os erros nos registros e corrigi-los.

Por meio deste método de contagem de materiais a acuracidade de estoque tende a melhorar, pois as recontagens de estoque fazem com que os envolvidos no processo tornem-se especialista nos processos de inventário, e dessa forma os erros são encontrados rapidamente e ajustados da melhor forma, sendo avaliados os processos, as pessoas e a tecnologia utilizada. Com isso, a contagem cíclica pode ser vista como uma espécie de processo de controle da qualidade dos registros de estoque, na ausência da contagem cíclica os registros de movimentação de materiais tendem a perder qualidade (WILSON, 1995).

Na mesma linha, Drohomeretski (2009) propõe um método para a implantação da CC. O método proposto é composto de cinco etapas, conforme a Figura 2. Estas envolvem desde atividades de planejamento da operação relacionadas ao dimensionamento dos recursos até o monitoramento e tomada de ações corretivas.

Figura 2 - Método proposto para implantação da CC

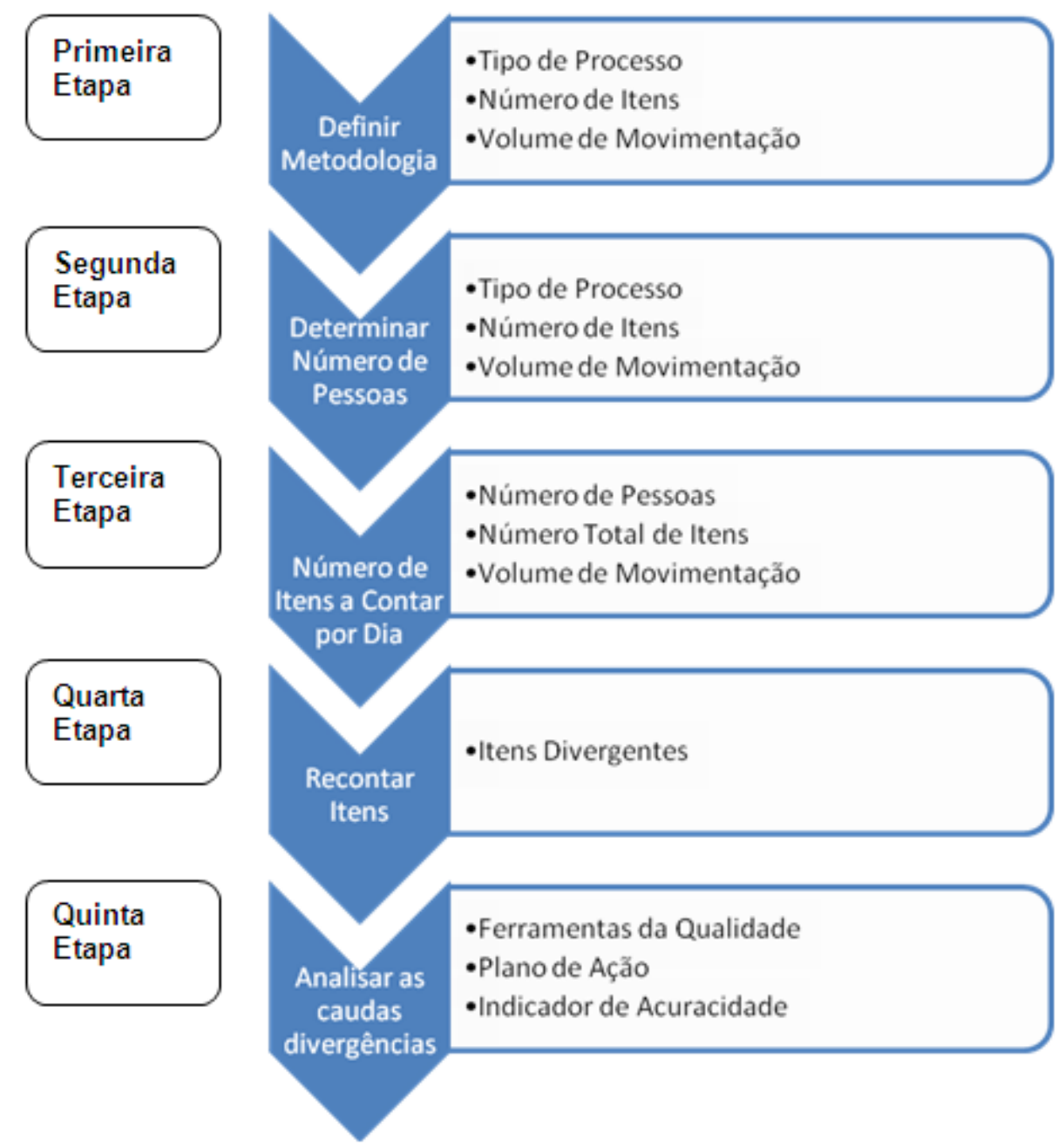

Fonte: Drohomeretski (2009) 
Para Gasnier (2002) o método de inventario cíclico pode levar em consideração a classificação de estoque de duas formas, sendo elas:

a) Classificação ABC: definida como classificação dos itens por custo de vendas, normalmente são os produtos ordenados de forma decrescente, tendo como base o volume de vendas anual. Para Bowersox et al (2007) essa classificação leva em consideração a regra dos 80/20 ou lei de Pareto, tendo como fundamento que $20 \%$ do volume de vendas resultam em $80 \%$ dos lucros e $80 \%$ das vendas correspondem a $20 \%$ dos lucros;

b) Classificação PQR: pode ser definida como classificação de popularidade. Para Gasnier (2007) essa classificação tem como base o número de transações realizadas durante o período anual em determinados SKU's, ou seja, o total de recebimentos, o total de despachos e o total combinado dessas transações para um determinado item, conforme ilustrado no Quadro 3.

Quadro 3 - Classificação da popularidade de materiais

\begin{tabular}{|c|l|}
\hline Classe P & Muito popular: itens com elevada movimentação, pelo menos uma transação diária \\
\hline Classe Q & $\begin{array}{l}\text { Popularidade média: aqueles que apresentam menos de uma transação por dia, ou seja, } \\
\text { freqüência intermediária }\end{array}$ \\
\hline Classe R & Baixa popularidade: aqueles que apresentam menos de uma transação mês, ou no semestre \\
\hline
\end{tabular}

Fonte: Gasnier (2002)

Após definição do critério de classificação a ser utilizado, o passo seguinte é estabelecer quantos itens vão ser contados e com qual freqüência será realizada as contagens, dessa forma faz necessário a elaboração de um plano de contagem. Bertaglia (2003) apresenta o número de contagens a serem realizadas utilizando a classificação $\mathrm{ABC}$ como critério, como podemos ver no Quadro 4.

Quadro 4 - Contagens de estoque, classificação ABC

\begin{tabular}{|c|c|c|c|}
\hline CLASSIFICAÇÃO & $\begin{array}{l}\text { QUANTIDADE } \quad \text { DE } \\
\text { ITENS }\end{array}$ & FREQUÊNCIA ANUAL & $\begin{array}{ll}\text { TOTAL } & \text { DE } \\
\text { CONTAGENS } & \end{array}$ \\
\hline $\mathbf{A}$ & 40 & 24 & 960 \\
\hline $\mathbf{B}$ & 60 & 12 & 720 \\
\hline $\mathbf{C}$ & 100 & 12 & 1.200 \\
\hline TOTAL & 200 & & 2.880 \\
\hline
\end{tabular}

Fonte: Bertaglia (2003)

Nesta linha Rossetti et al (2007) apresentam que para a realização da contagem cíclica é necessário primeiro realizar a escolha dos itens a serem contados, preparar a contagem, contar os itens, fazer a segunda contagem dos itens divergentes e por fim identificar e registrar as causas das divergências encontradas nas contagens. 
Em uma pesquisa realizada em sete indústrias Drohomeretski (2009) demonstra que as empresas com maior índice de acuracidade de estoque utilizam a contagem cíclica, apresentando uma diferença de acuracidade superior a $50 \%$ a uma das empresas pesquisadas que não utiliza a contagem cíclica.

Pode-se notar que por meio das contagens cíclicas os itens de maior representatividade para o estoque e ou para a empresa são contados com maior freqüência, tendo como objetivo reduzir erros de informações que possam comprometer o fluxo normal das atividades.

\section{Descrição do Estudo de Caso}

Nesta seção será apresentada a descrição do estudo de caso, partindo da descrição do instituto e as suas particularidades em sua gestão de estoque, as formas de controle e realização de inventários utilizados pela empresa e os resultados da implantação da contagem cíclica de materiais.

A empresa foco do estudo está situada em Curitiba-PR, com seis anos de atuação no mercado na área de ensino, é um instituto de ensino que ministra cursos em nível de pós-graduação na área odontológica, possui aproximadamente 55 funcionários, a empresa será identificada como EDUODONTO.

Para a EDUODONTO o estoque tem o objetivo de atender com materiais todos os cursos da instituição, possui elevado número de itens estocados e por este motivo atende prontamente todos os pedidos de materiais, fazendo deste ponto um dos diferenciais na prestação de serviço. Os produtos armazenados são divididos em produtos consignados (implantes dentários, componentes protéticos e instrumentos cirúrgicos) e produtos de uso e consumo (anestésicos, soros, luvas, gazes, ente outros).

Estes materiais são destinados a todos os atendimentos realizados em clinicas e laboratórios durante as aulas, ocorrendo o que podemos chamar de atendimento simultâneo, sem a ocorrência de pedidos ou solicitações anteriores por parte de professores e/ou alunos. Fato que torna complexo a gestão de estoque do instituto, pois qualquer falta de material interrompe a aula e automaticamente o tratamento do paciente. Mesmo com toda essa complexidade o fato é mais um diferencial da instituição, pois alunos não necessitam realizar planejamentos detalhados, situação que reduz tempo em salas de aulas e aumenta a vivência clinica durante o curso.

A gestão de estoque é realizada por meio de sistema informatizado que está em fase de implantação. Este sistema integra todos os setores da organização. O instituto trabalha com fluxo intenso de atendimentos e cursos. Os materiais são armazenados em gaveteiros e armários abertos, onde os implantes e componentes protéticos são condicionados nos gaveteiros e materiais de uso e 
consumos nos armários, a Figura 3 ilustra o sistema de armazenagem em gaveteiros, esse sistema é utilizado devido aos produtos serem de pequeno porte e fácil manuseio.

Figura 3- Sistema de armazenagem em gaveteiros

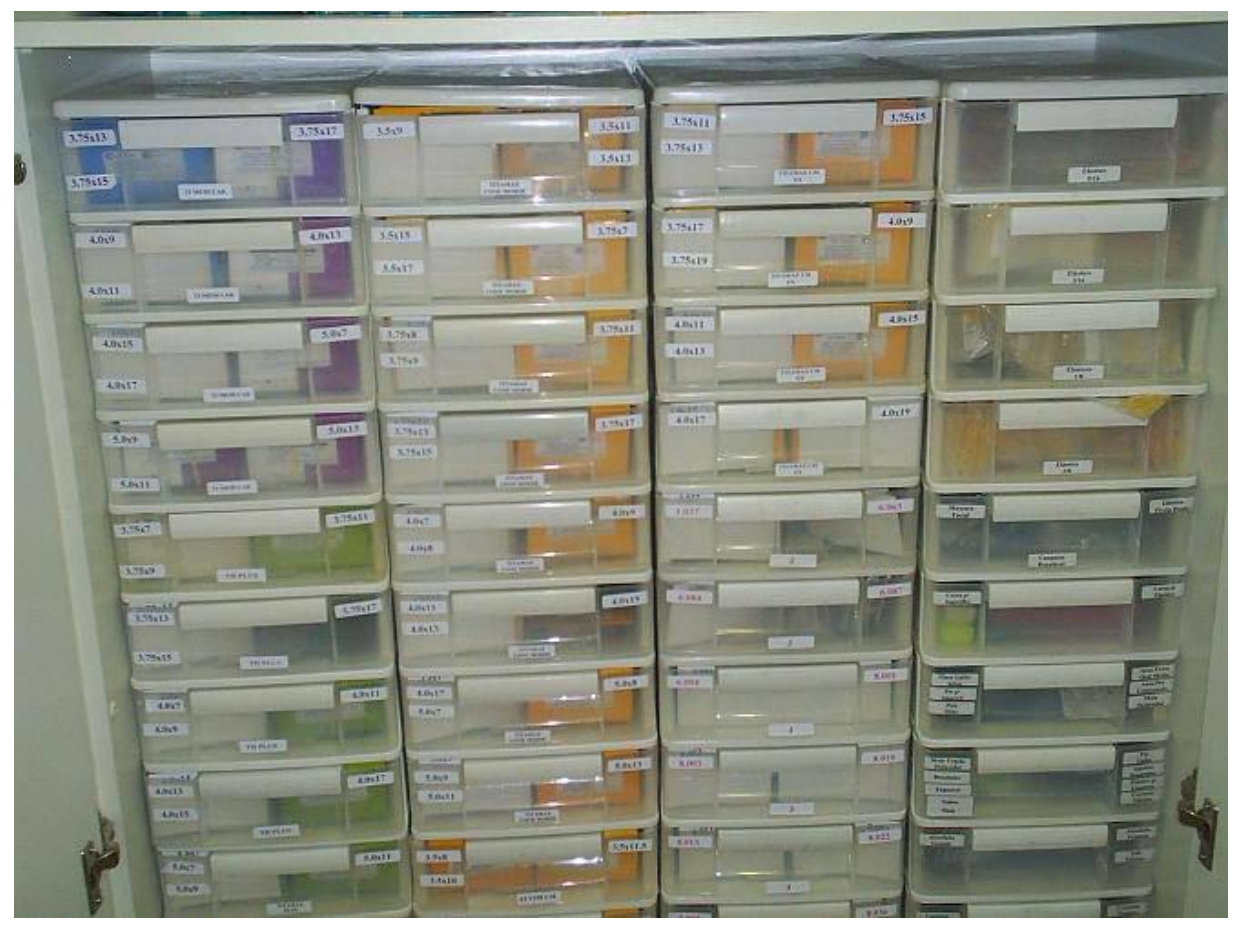

Fonte: EDUODONTO (2009)

O método de contagem de materiais utilizado pelo EDUODONTO se mostrava ineficiente, pois os dados apresentados apontavam baixa acuracidade, pois no inventário geral de 2008 o índice de acuracidade de estoque foi de $82,85 \%$.

O inventário geral é realizado anualmente na EDUODONTO. Essas contagens são realizadas normalmente no mês de dezembro e servem de preparação para a auditoria desempenhada pelo fornecedor. Onde o mesmo realiza uma contagem para verificação do saldo físico, onde os dados levantados são comprados com relatório de saldo consignado em aberto, e após confronto das informações os ajustes são realizados, tanto no sistema do fornecedor como no sistema do instituto foco do estudo.

Devido ao percentual baixo na acuracidade de estoque, situação que impacta no nível de serviço e nos custos da organização, a EDUODONTO elaborou um plano para a implantação da contagem cíclica de materiais.

Após aceitação da metodologia de inventário entre os envolvidos, houve resistência com relação às datas para as contagens. Pois devido ao fluxo intenso de atividades e ao número reduzido de funcionários a EDUODONTO observou que estabelecer datas pré-estabelecidas não seria a melhor forma, dessa maneira foram definidos os seguintes critérios para a realização das contagens cíclicas: 
a) As contagens seriam realizadas pelo menos uma vez por mês, de acordo com agenda semanal, e ainda com a conciliação das funções de rotina do setor;

b) Inicialmente os itens contados seriam apenas os consignados, ou seja, implantes e componentes protéticos;

c) As peças a serem contadas seriam aquelas que sofreram movimentação no período entre um inventário e outro, sendo que o primeiro teria como base o inventário geral do início do ano de 2008.

Nota-se que os critérios adotados para realização das contagens fugiram um pouco do método de contagem cíclica apontado pela literatura, porém segundo o entrevistado, devido às particularidades da organização essa foi à melhor forma para a realização das contagens, e ainda essa metodologia foi adotada apenas para os produtos consignados. Após a definição da estratégia para a realização dos inventários, a EDUODONTO iniciou o processo de contagem cíclica.

Ao longo das visitas foram coletados dados relativos a quatro rodadas de contagem cíclica. A Tabela 1 ilustra os índices de acuracidade de estoque ao longo do período das contagens.

Tabela 1 - Evolução do índice de acuracidade de estoque

\begin{tabular}{lc}
\hline Contagem & $\begin{array}{c}\text { Índice de Acuracidade } \\
\text { de }\end{array}$ \\
\hline Estoque
\end{tabular}

Fonte: Dados coletados na EDUODONTO (2009)

Com a implantação da contagem cíclica a EDUODONTO conseguiu identificar as causas estavam gerando as divergências de estoque, segue abaixo as principais causas identificadas:

a) Duplicidade dos pedidos de reposição;

b) Solicitações erradas,

c) Troca de códigos;

d) Erros nos processos de armazenagem;

e) Erros nas contagens;

f) Troca de códigos na saída dos produtos.

Após identificação das principais causas a EDUODONTO aplicou medidas corretivas e a padronização das atividades para que os erros fossem reduzidos. O Quadro 5 aponta quais foram os procedimentos adotados para as causas das divergências de estoque identificadas. 
Quadro 5 - Medidas corretivas no controle de estoque

\begin{tabular}{|c|c|}
\hline CAUSA RAIZ & MEDIDA PREVENTIVA \\
\hline Duplicidade dos pedidos de reposição & Conferência das ordens de compras \\
\hline Solicitações erradas, troca de códigos & Conferência das ordens de compras \\
\hline \multirow{3}{*}{ Erros nos processos de armazenagem } & Separação previa dos itens por categoria \\
\hline & $\begin{array}{l}\text { Programação para o não acumulo de materiais nas áreas } \\
\text { de recebimento, peças aguardando armazenagem }\end{array}$ \\
\hline & Treinamento contínuo dos envolvidos \\
\hline Erros nas contagens & Treinamento dos envolvidos \\
\hline Troca de códigos na saída dos produtos & $\begin{array}{l}\text { Conferência dos itens solicitados no ato da entrega, } \\
\text { confirmação com os profissionais/solicitantes }\end{array}$ \\
\hline
\end{tabular}

Fonte: EDUODONTO (2010)

\section{Análise dos dados}

A presente seção tem por objetivo analisar o processo de implantação da contagem cíclica e os seus resultados alcançados, citados na Seção 4. Além disso, descreve também as particularidades da organização no que se refere ao controle de estoque, apontando as formas de controle e inventários utilizados.

Tendo como base o referencial teórico que sustenta o presente trabalho, notamos que as descrições citadas por autores se mostraram eficientes. Pois como detalhado a organização utilizava apenas os inventários anuais como ferramenta de controle e ajustes de erros de saldos. Este citado por Sucupira e Pedreira (2009) como método ineficaz para ajustes, pois devido à visão patrimonialista este se preocupa somente com o valor dos produtos e não com os problemas oriundos dos baixos percentuais de acurácia. Dessa forma os dados apresentados no Gráfico 2 demonstra que o baixo percentual de acuracidade, este com valor igual $82,85 \%$ de acertos de saldos deve-se a metodologia que era utilizada, procedimento que não atendia de forma eficaz os controles de saldos e ainda impactava no nível de serviço da organização. As causas não eram identificadas, dificultando controle sobre os problemas, neste sentido se mostrou necessário uma ferramenta que atendesse de forma eficaz os processos de estoque, auxiliando no controle de saldos e causa raízes.

O critério adotado pela EDUODONTO para a realização das contagens cíclicas foi definida por meio da visualização de suas operações numa visão macro, pois tal metodologia de contagem necessitou de alguns ajustes para que pudesse ser implantada. Como definido por Gasnier (2002) existem diferentes métodos, cada qual com suas indicações e limitações, o que torna necessário o conhecimento dos processos e suas peculiaridades para a escolha do mais adequado. Notou-se que as contagens não foram realizadas diariamente, mas sim mensalmente, tomando como critério para 
definição das peças a serem contadas a classificação PQR, onde através de relatório de movimentação os itens eram identificados, e ainda o plano definido pela organização é de finalizar o ano de 2009 com pelo menos 6 contagens cíclicas e 2 geral. No entanto, devido ao tempo de estudo foi somente possível acompanhar o resultado de 4 contagens cíclicas e um inventário geral. Neste sentido a Tabela 2 aponta alguns pontos importantes nas contagens cíclicas realizadas no período de avaliado.

Tabela 2 - Dados importantes das contagens cíclicas

\begin{tabular}{lc}
\hline Dados das Contagens & TOTAL \\
\hline Total de itens contados & 869 \\
Média de itens por contagem & 217 \\
Média de itens contados por dia & 11 \\
Média de pessoas envolvidas nos processos de contagens & 3 \\
\hline Fonte: EDUODONTO (2009) &
\end{tabular}

A média de itens contados por dia foi identificada apenas para consulta e verificação de quantidade, pois segundo dados apresentados pela EDUODONTO o número de peças por item é expressivo. Em relação aos ajustes de saldos, estes são realizados pelo próprio setor, não necessitando de liberação da gerencia da instituição, dessa forma o Quadro 6 aponta os critérios adotados para os acertos de estoque.

Quadro 6 - Critérios para ajustes de saldos

\begin{tabular}{|l|l|}
\hline DIVERGÊECIA & \multicolumn{1}{|c|}{ MEDIDA ADOTADA } \\
\hline Sobras & $\begin{array}{l}\text { Peças são identificadas e devolvidas ao fornecedor, onde procedimento gera crédito para } \\
\text { organização, abatendo boletos futuros }\end{array}$ \\
\hline Faltas & $\begin{array}{l}\text { Peças são identificadas e solicitadas para o fornecedor, fatura normal para a empresa, item } \\
\text { volta a compor saldo consignado }\end{array}$ \\
\hline
\end{tabular}

Fonte: EDUODONTO (2009)

Verificou-se que com a implantação das contagens cíclicas o percentual de acurácia se elevou significativamente. Pois as causas foram sendo identificadas e ações corretivas foram sendo tomadas para que os erros fossem sendo minimizados, assim o Gráfico 1 ilustra a melhora gradativa na acuracidade de estoque. 
Gráfico 1 - Evolução do índice de acuracidade com a implantação da contagem cíclica

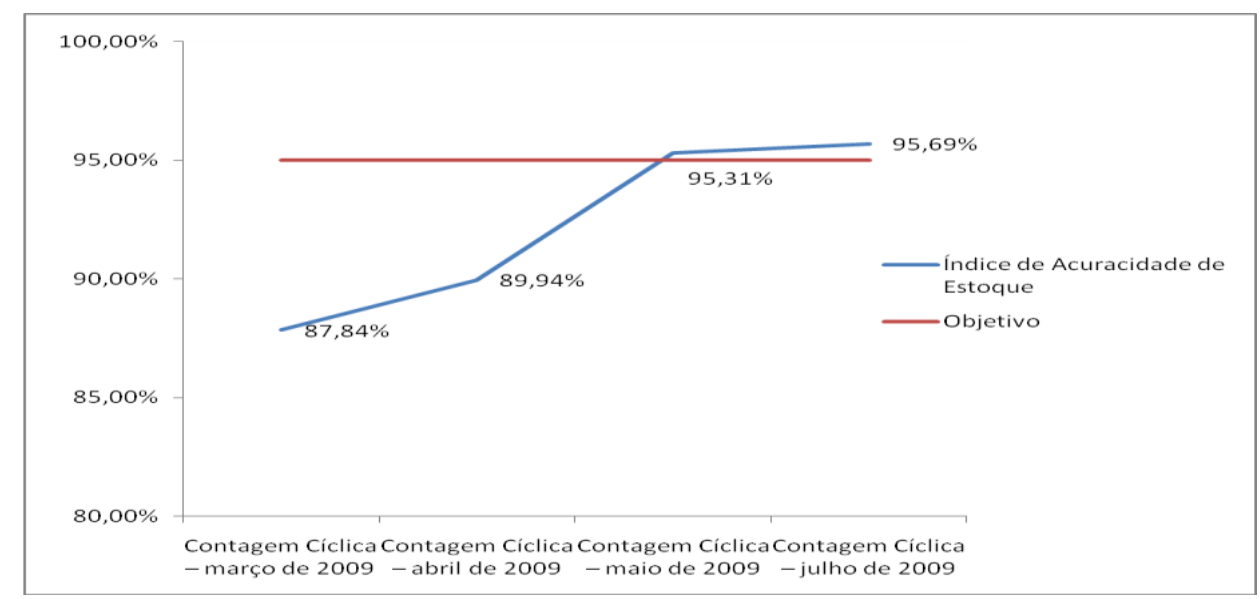

Fonte: Os autores (2012)

Com as contagens mensais e identificação da causas a melhora no índice de acertos de estoque foi expressiva. Dessa forma, o Gráfico 2 compara o percentual de acurácia do inventário geral de 2008 com o realizado no mês de Julho de 2009 após a implantação da contagem cíclica.

Gráfico 2 - Comparativo inventário geral 2008 e 2009

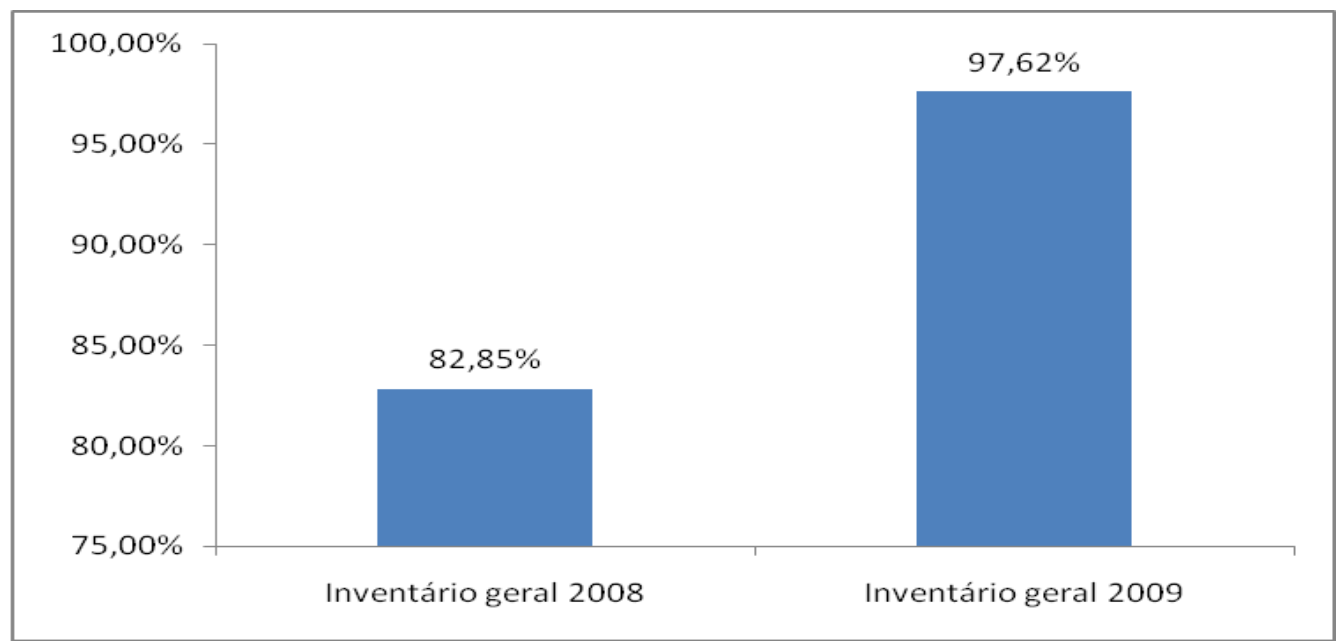

Fonte: Os autores (2012)

Pode-se observar que com a implantação da metodologia de contagem cíclica o percentual de acertos de saldos no estoque teve um aumento de 14,77\%. Essa melhora no percentual de acuracidade trouxe vários benefícios para o setor e para a organização, pois com essa conquista os problemas com falta de materiais e com o não atendimento de alguns pedidos foram reduzidos. Além deste ponto o interesse da organização é atingir um percentual superior a 95\% no inventário geral no final das atividades do ano de 2009, e assim reduzir custos com as divergências de saldos.

\section{Considerações Finais}


O desenvolvimento do presente artigo objetivou analisar o impacto da contagem cíclica para o controle de estoque em um instituto de odontologia. Pode-se verificar que os resultados alcançados pela EDUODONTO com a implantação da contagem cíclica devem-se principalmente do processo de identificação das causas de divergência de estoque dentro da organização.

O artigo contribui, além de evidenciar os benefícios da implantação da contagem cíclica em um instituto de educação da área da saúde odontológica, também demonstra a importância da implantação de medidas preventivas para atacar as causas de erros. $\mathrm{O}$ que pode ser verificado no caso estudado por meio do apontamento da melhoria no percentual de acurácia, resultado conquistado com as medidas adotadas para que os erros não acorressem novamente. Notou-se também que os procedimentos adquiridos foram simples e sem custos adicionais para a organização trazendo benefícios significativos.

O aumento do percentual de acurácia se mostrou satisfatório, sendo este de 14,77\% sobre os dados apresentados no inventário geral de 2008. Ou seja, a EDUODONTO passou de um índice de acuracidade de $82,85 \%$ para $97,62 \%$. Assim podemos concluir que a contagem cíclica é um método importante para a melhoria da acuracidade de estoque, pois esta medida consegue elevar a confiabilidade dos saldos de estoque, por meio de contagens com frequência determinadas, fazendo com que os envolvidos nos processos se tornem especialistas no combate a causas das divergências de estoque.

\begin{abstract}
The search for effective methods of inventory control that reflect reliable data for planning and implementing operations becomes a requirement for organizations to survive in the market. So the quality of the information of inventory balances makes the efficiency of processes increases. Therefore, it is necessary to use methods that assist in inventory control, increasing the percentage of accuracy of stock. In this line, this paper aims to examine the contribution of the cycle count in inventory control in a dental institute. To achieve the proposed objective was used as a case study methodological approach. With the implementation of cycle counting of materials could be identified which factors were impacting on information from sales of stock, with this the institute has implemented actions to eliminate the main causes of differences. The results of the deployment were significant because the increase was $14.77 \%$ accuracy in inventory.
\end{abstract}

Key-words: Inventory control, accuracy, cycle counting, dentistry institute.

\title{
Referências
}

ACCIOLY, F. et al Gestão de Estoque. Rio de Janeiro: FGV, 2008.

ARNOLD, T. J. R. Administração de materiais: uma introdução. São Paulo: Atlas, 1999.

BERTAGLIA, P. R. Logística e gerenciamento da cadeia de suprimentos. São Paulo: Saraiva, 2006.

BOWERSOX, D. J et al Gestão da Cadeia de Suprimentos e Logística. Rio de Janeiro: Elsevier, 2007. 
CORRÊA, H. L. et al Planejamento, Programação e Controle da Produção. São Paulo: Atlas, 2001.

DROHOMERETSKI, E. Um estudo do impacto das formas de controle de Inventário na acuracidade de Estoque. 2009. 157 f. Dissertação (mestrado) - Programa de Pós-Graduação em Engenharia de Produção e Sistemas. Pontifícia Universidade Católica do Paraná, Paraná, 2009.

FERNANDES, L. A. \& PIRES, S. R. I. Impactos da falta de acurácia de estoques e proposições para melhorias: estudo de caso em uma empresa fabricante de autopeças. XII SIMPEP - Bauru, 2005.

GASNIER, D. A dinâmica dos estoques: guia prático para planejamento, gestão de materiais e logística. São Paulo: IMAM, 2002.

ROSSETTI, M. D. et al Inventory Accuracy Improvement via in a Two-Echelon Supply Chain. The Proceedings of the 2007 Industrial Engineering Reserarch Conference, Dallas, Texas, 2007.

SHELDON, D. H. Achieving Inventory Accuracy: A Guide To Sustainable Class A Excellence In 120 Days. Hardcover: J. Ross Publishing, 2004.

SUCUPIRA, C. \& PEDREIRA, C. Inventários Físicos: A importância da acuracidade dos estoques. <Disponível em: http://www.cezarsucupira.com.br/artigos>. Acessado em 30 de maio de 2009.

VIANA, J. J. Administração de Materiais: um enfoque prático. São Paulo: Atlas, 2000.

WILSON, J. M. Quality control methods in cycle counting for record accuracy management. International Journal of Operations \& Production Management, v. 15 n. 7, p. 27-39, 1995.

cross ref

Dados dos autores:

Nome completo: Everton Drohomeretski

Filiação institucional: FAE Centro Universitário - FAE - Curitiba - Brasil

Função ou cargo ocupado: Professor Centro Universitário Franciscano do Paraná (FAE)

Endereço completo para correspondência: Centro Universitário Franciscano do Paraná,

Departamento de Engenharia de Produção. Rua 24 de maio, 135, Centro, CEP:80230-080 -

Curitiba, PR - Brasil.

e-mail: profeverton.d@hotmail.com

Nome completo: Juliano Anderson de Souza

Filiação institucional: PUC-PR - Curitiba - Brasil

Função ou cargo ocupado: Funcionário do Instituto Latino Americano de Pesquisa e Ensino

Odontológico

e-mail: jas_juliano@yahoo.com.br

Enviado em: 24/02/2011

Aprovado em: 04/06/2012 